\title{
Modern Analytical Chemistry. Selected papers from the 11th International Students' Conference, Prague 2015
}

\author{
Karel Nesměrák ${ }^{1}$ (1) · Tomáš Navrátil ${ }^{2}$
}

Received: 28 June 2016/Accepted: 5 July 2016/Published online: 20 July 2016

(C) Springer-Verlag Wien 2016

\begin{abstract}
"The beginning is the most important part of the work" says Plato. This is also true for the beginnings of the career of young scientists. It was the intention of the founders of the international students' conference series "Modern Analytical Chemistry" at the Department of Analytical Chemistry, Faculty of Science, Charles University in Prague in 2004 to create a suitable "start-up" environment for the first decisive kick off. With its aim at the support of the creativity and research activities of Ph.D. students of analytical chemistry, the conference helps in the development of skills connected with the presentation of research results to the wide scientific community. This conference also provides the floor for discussions and exchange of experiences, and at the same time, it lays the ground for the long-term mutual cooperation and contributes to mastering the English language. Briefly to say, the conference helps with scientific beginnings of the participants.

We are very pleased that this conference has become an attractive platform for the young analytical chemists. The growth of this conference is indeed impressive-from the very modest start in 2004 with only nine participants to fifty-five in 2015 coming from five countries (Czech Republic, Germany, Poland, Slovakia, and Spain). The total number of participants reached 320 . The growth of the number of the young researchers who attended this conference has been mirrored by the increasing quality of
\end{abstract}

Karel Nesměrák

nesmerak@natur.cuni.cz

1 Department of Analytical Chemistry, Faculty of Science, Charles University in Prague, Prague, Czech Republic

2 J. Heyrovský Institute of Physical Chemistry of the AS CR, v.v.i., Prague, Czech Republic presentations of the results in various fields of analytical chemistry. In addition, this is what makes the organization of this meeting very fulfilling and satisfactory.

To offer the possibility for the improvement of scientific writing skills, the conference proceedings have been established (now available on the conference webpage: natur.cuni.cz/isc-mac/). The growing quality of the contributions led us to think of special issue of a scientific journal. As Editors of this special issue of "Monatshefte für Chemie", we would like to express our deep gratitude to the Editor-in-Chief of the journal, Prof. Dr. Peter Gärtner, and the Managing Editor, Dr. Christian Hametner, for their generous agreement to publish selected papers presented at the 11th conference. We also would thank all authors for their great effort to contribute with results of their research, all referees for valuable comments that helped to improve the quality of the manuscripts, and to the staff of the Publisher, Springer Vienna, for their contribution to the special issue release.

Let us to express our hope that published contributions assure the readers that analytical chemistry - thanks also to the new generations of analytical chemists-remains exciting and steadily developing science with bright perspective and new, unsuspected ways of its innovation and application. 